\title{
Enhancement, Authenticity, and Social Acceptance in the Age of Individualism
}

\author{
By Daniel Kelly and Nicolae Morar ${ }^{1}$ \\ OPC forthcoming in American Journal of Bioethics Neuroscience
}

\section{Introduction}

Conrad et al's project is intriguing and potentially pathbreaking. We identify one particular line of inquiry suggested by their paper, offer some suggestions about how to clarify and conceptualize it, and make the case for why we think it is likely to be an especially fruitful one to pursue going forward.

We agree that empirical research on public attitudes about cognitive enhancements is important for a number of reasons. Knowing the range and distribution of public attitudes sheds light on how socially acceptable emerging technologies are likely to be, whether they are likely to be embraced as a welcome advance, considered distasteful, or rejected as outright unethical. Perhaps more importantly, this research provides a window into the kinds of moral reasons that are likely to get traction and be persuasive in the ongoing debates about cognitive enhancements. Moreover, since it is now evident that human reasoning is far from ideal, and sensitive to a host of extrarational factors (Ariely 2009; Kahneman 2012; Mercier and Sperber 2017), Conrad et al's focus on how different metaphors and frames influence people's reasoning about cognitive enhancements is both valuable and shrewd.

We think the power of frames and metaphors that draw on the cluster of values related to authenticity and self-expression deserves more sustained attention. Against the backdrop of our

\footnotetext{
${ }^{1}$ Author names are listed in alphabetical order, which reflects equal contribution to the authorship of the article. Address correspondence to Nicolae Morar, The Environmental Studies Program and the Department of Philosophy, University of Oregon, 1295 University of Oregon, Eugene, 97403, USA. E-mail: nmorar@uoregon.edu
} 
endorsement of their overall project, we can develop our suggestion by raising a mild objection to the target article, where Conrad et al make initial inroads into what we think will be a rich vein to mine. They describe some of their materials as casting cognitive enhancements in a questionable light, and so likely to nudge participants to judge them negatively, because such enhancements allow people to achieve "inauthentic success":

"the steroid metaphor advocates minimizing effort, thus rendering achievements inauthentic. Maximizing potential and inauthenticity are, respectively, commonly invoked arguments for and against the use of CE. ... whereas the negative frame of CE "helping us to minimize effort needed to perform" was meant to capture the "inauthentic success" anti-CE argument" (Conrad et al, XX)

We agree in general that inducing people to construe cognitively enhanced accomplishments as 'unearned' or 'undeserved' is likely to induce negative attitudes. But we think that describing the success as 'inauthentic' is misleading, or at least elides some of the more interesting connotations of the term, especially in context of the present set of concerns.

\section{The Many Faces of Authenticity}

A number of bioethicists have noted that, perhaps unsurprisingly, the concept of authenticity has loomed large in debates about enhancement technologies. More surprisingly is that both proponents and critics have appealed to considerations of authenticity to make their opposing cases (Parens 2005). Some proponents have used this concept to argue that such technologies are not just morally permissible but valuable, on the grounds that they increase freedom and autonomy. Enhancements give people the tools to enact and express their genuine natures and to fashion an identity that matches their inner sense of who they really are, which in turn helps them to realize their inner goals and personal values, and ultimately achieve self-fulfillment. Critics, on the other hand, see these same kinds of technologies as morally corrosive, arguing that they contribute to the corruption of individual selfhood and the human nature in which it is rooted. Rather than enable the 
expression of a true inner self, this line of argument goes, the abilities a person gains through many enhancement technologies more often tempt them away from authenticity and towards artificiality. The sort of cognitive and behavioral augmentation they provide are manufactured and fake, thus tantamount to cosmetic distortions of who a person really is.

Kadlac (2018) has recently brought more clarity to the wooly concept of authenticity. He distinguishes two importantly different senses of the idea that are often conflated. On the one hand, the value of authenticity is associated with the moral ideal of being true to your own self. He nicely illustrates this ideal with an example (from Schechtman 2004) of how a person might fail to live authentically in this sense, asking us to consider

“a 1950's housewife who is caught between the expectations placed on her by her social role - expectations that require her to attend primarily to domestic matters - and strong competing 'desires to take courses at the local college, spend time with her friends, apply for part-time jobs, or get involved in political causes. Such a person might indeed fail to be true to herself by persisting in the domestic routine." (Kadlac, 794)

On the other hand, authenticity is often contrasted fakery and the kind of phoniness to which Holden Caulfield was famously sensitive. Kadlac unpacks this in terms of self-presentation. While the first sense of authenticity points to an ideal that regulates the inner and outer aspects of an individual, and the relation between a person's internal desires and her overt actions, this second ideal is more thoroughly outer-oriented. It governs inconsistencies in the way a person acts and presents herself in different contexts, and concerns the relation between what a person says about himself to different people and what is actually true of that person, of the ways a person presents herself in different social situations, including how a person is "when no one is looking." (Kadlac p 793, our italics). Schechtman's housewife might be inauthentic in the first sense but not the second, while a person who uses a cognitive enhancement to help achieve one of her longstanding goals but then lies to her friends about using it is being inauthentic in the second sense but not the first. 
Kadlac uses this distinction between senses of authenticity to make a normative argument that there is nothing morally wrong with enhancements per se, and nothing wrong or inauthentic (in the Schechtman sense) about using them to achieve one's goals or even to remodel one's identity to better fit their sense of self. However, he holds that a person can be inauthentic (in the Caulfield sense) with respect to her use of enhancements if she publicly presents herself as unenhanced; one is being unethical "to the degree that one passes off oneself and one's achievements as something they are not." (Kadlac, 790). Kadlac's normative argument strikes us as plausible, and we suspect we are not alone. We also suspect that Holden Caulfield is not alone in being keenly sensitive to the social cues and subtle dynamics regarding authenticity, self-presentation, consistency, and phoniness. Our aim is not to assess Kadlac's argument, but rather to use the discussion and distinction to draw attention to the many different facets of concern about authenticity that are likely shaping public attitudes about enhancement.

\section{Authenticity, Social Acceptance, and the Logic of Individualism}

There is good reason to think that concern about authenticity plays an especially large and complicated role in shaping public attitudes about cognitive enhancement because concern about authenticity plays a large and complicated role in Western moral thought more generally (Taylor 1989). Ours is a culture of individualism. Individuals are the primary locus of ethical significance, and many of our core values flow from the centrality of individuals to Western morality: liberty, freedom, personal responsibility and autonomy, and of course authenticity.

Elliott's work $(2004,2011)$ is devoted to the philosophical exploration of the connections between bioethical issues surrounding enhancement and individualistic values surrounding authenticity. It identifies more potentially salient nuances in those conceptual connections, and 
provides illuminating context for the more specific questions it addresses. For example, Elliott notes a theme in the way users of enhancements conceive of their effects: they tend to draw on the vocabulary of authenticity. More specifically, they often describing the technology, be it a pill or a device or a procedure, as functioning to remove obstacles to their authentic expression and selffulfillment. Upon enhancement, they have become more attuned to their inner feelings, are only now able to be the kind of person they have always felt themselves to genuinely be, are finally able to experience their real identity and unleash their true self.

Alongside Kadlac's more focused discussion, Elliott's project provides support for our contention that future empirical exploration of public attitudes about different kinds of cognitive enhancement should focus on the thicket concerns attached to authenticity. We think it is no coincidence that when users wish to justify and legitimize their use of enhancement, they do so in the language of authenticity and self-expression, and thus the logic of individuality. In virtue of its position of prominence in our Western moral framework, that logic and language is likely to be effective: if a behavior, practice, or technology can be construed as contributing to the realization of authenticity, self-expression, and other individualistic values, it is more to be socially accepted, regarded as permissible in the eyes of the public.

These are our culture's magic words, today's versions of "open sesame" or "abracadabra": they license, they legitimize, they open doors in the social world and make us likely to collectively allow the possible to become actual. That is the general hypothesis we have been developing, anyway - that framing and justifying various types of cognitive enhancements using the language of individualism and authenticity make them more likely to become socially palatable and to be seen as just one more legitimate route to self-fulfillment or valid form of self-creation (DeGrazia 2000). The hypothesis is empirically tractable, and one that could be addressed using the resources of Conrad et al's exciting research project. Explicit arguments can draw on these magic words, but their work 
suggests frames and metaphors that resonate with individualistic values will be more effective in shaping public attitudes. We hope to have made a persuasive case that frames and metaphors associated with the many faces of authenticity deserve attention in future research.

\section{References}

1) Ariely, D. (2010). Predictably Irrational: The Hidden Forces that Shape Our Decisions. New York: Harper Collins.

2) DeGrazia, D. (2000). "Prozac, Enhancement, and Self-Creation," Hastings Center Report 30(2):34-40.

3) Elliott, C. (2004). Better Than Well: American Medicine Meets the American Dream. New York: Norton.

4) Elliott, C. (2011). "Enhancement Technologies and the Modern Self," Journal of Medicine and Philosophy. 36: $364-374$.

5) Kadlac, A. (2018). "The Challenge of Authenticity: Enhancement and Accurate SelfPresentation," Journal of Applied Philosophy, 35(4): 790 - 808.

6) Kahneman, D. (2011). Thinking Fast and Slow. New York: Farrar, Straus and Giroux.

7) Mercier, H. and Sperber, D. (2017). The Enigma of Reason. Cambridge, MA: Harvard University Press.

8) Parens, E. (2005). "Authenticity and Ambivalence: Toward Understanding the Enhancement Debate," The Hastings Center Report. 35. 34-41.

9) Schechtman, M. (2004). "Self-expression and self-control," Ratio XVII, 409-427.

10) Taylor, C. (1989). Sources of the Self: The Making of Modern Identity. Harvard University Press. 